\title{
OCUPAÇÕES SECUNDARISTAS EM MINAS GERAIS: SUBJETIVAÇÃO POLÍTICA E TRAJETÓRIAS
}

\author{
Luís Antonio Groppo ${ }^{1}$ \\ Mara Aline Oliveira ${ }^{2}$
}

\begin{abstract}
RESUMO: São analisadas, por meio de entrevistas semiestruturadas, as experiências de catorze estudantes nas ocupações secundaristas em Minas Gerais, em 2016, enfatizando como a dimensão educacional desse movimento afetou as suas trajetórias políticas. A ocupação pode ser considerada um processo de subjetivação política, conforme Jacques Rancière, em que a ativa participação política em uma ação coletiva de grande impacto formativo acionou processos de desidentificação em relação a tradicionais papéis sociais, em especial os de adolescente, estudante e mulher. Apesar de ser constatado que houve poucos engajamentos efetivos em organizações políticas, verifica-se a prontidão para a participação política e a conversão das experiências da ocupação em práticas definidas como progressistas no cotidiano.
\end{abstract}

Palavras-chave: Ocupações. Estudantes do Ensino Médio. Subjetivação política.

\section{STUDENT OCCUPATIONS IN MINAS GERAIS, BRAZIL: POLITICAL SUBJECTIVATION AND TRAJECTORIES}

\begin{abstract}
The experiences of fourteen students in the student occupations in the Brazilian state of Minas Gerais in 2016 are analyzed, through semi-structured interviews, addressing how much the educational dimension of this movement has affected their political trajectories. The occupation can be considered a process of political subjectification, in the sense given by Rancière, in which the active political participation in a collective action of great formative impact triggered processes of deidentification in relation to traditional social roles. Despite the fact that there were few effective engagements in political organizations, there is a readiness for political participation and the conversion of the experiences of the occupation into practices defined as progressive in everyday life.
\end{abstract}

Keywords: Occupations. High school students. Political subjectivation.

Este artigo comunica resultados da pesquisa "Ocupações Secundaristas no Brasil em 2015 e 2016: Formação e Autoformação das/dos Ocupas como Sujeitos Políticos”, aprovada pelo Conselho Nacional de Desenvolvimento Científico e Tecnológico (CNPq) com Bolsa de Produtividade em Pesquisa com o processo 02633/2018-9 e por Chamada Universal com o processo n. 428160/2018, e da pesquisa “Ocupações Secundaristas no Sul de Minas e o Conceito de Educação Menor”.

1.Universidade Federal de Alfenas- Programa de Pós-graduação em Educação - Alfenas (MG), Brasil. E-mail: luis.groppo@unifal-mg.edu.br 2.Universidade Federal de Alfenas- Programa de Pós-graduação em Educação - Alfenas (MG), Brasil. E-mail: maraadvsindute@gmail.com Editor de Seção: Adriana Dragone Silveira 


\title{
OCUPACIONES DE ESTUDIANTES DE SECUNDARIA EN MINAS GERAIS, BRASIL: SUBJETIVACIÓN POLÍTICA Y TRAYECTORIAS
}

\begin{abstract}
RESUMEN: Se analizan, a través de entrevistas semiestructuradas, las experiencias de catorze estudiantes en las ocupaciones del estado brasileño de Minas Gerais en 2016, abordando cómo la dimensión educativa de este movimiento ha afectado sus trayectorias políticas. La ocupación puede ser considerada un proceso de subjetivación política, en el sentido dado por Rancière, en el que la participación política activa en una acción colectiva de gran impacto formativo desencadenó procesos de desidentificación en relación con los roles sociales tradicionales. Apesar de que hubo pocos compromisos efectivos en las organizaciones políticas, existe una disposición para la participación política y la conversión de las experiencias de la ocupación en prácticas definidas como progresistas en el cotidiano.
\end{abstract}

Palabras-clave: Ocupaciones. Estudiantes de secundaria. Subjetivación política.

\section{Introdução}

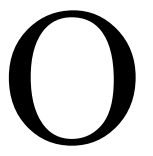

artigo analisa dados sobre as ocupações escolares ocorridas em Minas Gerais (MG) no segundo semestre de 2016. As ocupações, naquele momento, assumiram caráter nacional, conformando uma ação coletiva que se opunha a iniciativas do governo Temer, especialmente à Medida Provisória n. 746 - que, transformada na Lei n. 13.415/2017, reformou o Ensino Médio no país - e à Proposta de Emenda Constitucional n. 241 (PEC 241) - posteriormente PEC 55 e, enfim, Emenda Constitucional n. 95 -, que alterou o Regime Fiscal da União, congelando por vinte anos os gastos sociais.

Neste artigo, apresentaremos os resultados preliminares da pesquisa, a partir de um conjunto de dados constituído de catorze entrevistas com jovens de quatro municípios do estado de Minas Gerais. A pesquisa tem sido levada a efeito por equipes em nove estados, envolvendo doze Instituições de Educação Superior (IES) ${ }^{1}$, entre as quais a equipe de MG, organizada em torno do Grupo de Estudos sobre a Juventude da Universidade Federal de Alfenas (UNIFAL-MG), e tem como objetivo geral compreender os impactos da participação nas ocupações na (re)constituição de jovens que ocuparam suas escolas (ocupas) como sujeitos políticos.

A formação de sujeitos políticos tem sido concebida a partir da noção de subjetivação política de Jacques Rancière (1996), noção essa que possibilita compreender a constituição de adolescentes e jovens em sujeitos políticos como processo complexo, criativo, tenso, relacional e sempre inconcluso, no qual tais jovens são também são atuantes e, em parte, autoconstroem-se na mesma medida em que se constroem em suas relações com pessoas adultas. No mesmo sentido, busca-se compreender, a partir da análise dos sentidos desses processos de subjetivação política, como o mergulho dos sujeitos nessa ação coletiva impactou as suas trajetórias políticas. Metodologicamente, trata-se de uma pesquisa qualitativa, que considera a diversidade de cenários e das experiências das ocupações, destacando as entrevistas de caráter semiestruturado com estudantes que participaram ativamente das ocupações de escolas de Ensino Médio, tendo em vista analisar, de modo denso, o impacto do movimento em suas formações e trajetórias.

Dito de outra maneira, o artigo busca compreender se e como a experiência de adolescentes ocupas repete o que Bringel e Pleyers constatam sobre a atuação em ações coletivas, a partir do exemplo de junho de 2013: “[m] esmo que efêmeras, as experiências vividas nas mobilizações e em evento de protesto produzem 'marcas' 
nos participantes, reforçando a propensão a que possam se engajar politicamente no futuro e podendo, ademais, transformar, no médio e longo prazo, suas identidades sociais e seus valores políticos” (2015, p. 11).

\section{Socialização Política e Subjetivação Política}

A sociologia política, inicialmente, desenvolveu um conceito de socialização bem mais rígido e estreito em relação ao que temos atualmente (OPPO, 1998), herdado da noção de socialização de Durkheim (1978), em que crianças, adolescentes e jovens são seres nos quais predomina o "ser natural", a ser reprimido e reorganizado como "ser social" por meio da ação de sujeitos e instituições adultas. Os estudos sobre socialização política, como decorrência, preocupavam-se, fundamentalmente, com o modo como a pessoa se adequaria a um modelo de cidadania, formado a partir das expectativas tanto das pessoas adultas quanto das instituições políticas vigentes.

Um importante exemplo do esforço para reavaliar o conceito de socialização é Juarez Dayrell, que o reviu e alargou a partir da constatação de que os sujeitos, ou atores, sociais são participantes ativos de sua própria socialização (DAYRELL, 2003).

O mesmo empenho se viu no conceito de socialização política. Seu foco foi se ampliando e passou a considerar outras instituições para além da família e escola, inclusive os grupos de pares constituídos por crianças e adolescentes, e outros momentos do ciclo da vida, em especial a juventude. Tal qual nos processos de socialização em geral, uma sinfonia de instituições e influências parecem ecoar nos processos de socialização política, tornando possível e necessário o exercício da escolha ou da decisão pelos indivíduos, que nunca é totalmente livre, mas dependente de inúmeros fatores sociais. Os trabalhos de Kimi Tomizaki, no Brasil, em diálogos com autoras francesas como Anne Muxel, são um bom exemplo desta concepção:

O campo de pesquisas sobre a socialização política permite interrogar a maneira como as pessoas não somente exprimem opiniões, tomando parte nas decisões políticas e sendo ativas quanto à expressão de sua cidadania, mas também, mais amplamente, o modo como os indivíduos interpretam e dão sentido ao mundo ao seu redor e a seu lugar na sociedade (MUXEL apud TOMIZAKI; DANILIAUSKAS, 2018, p. 349).

Contribuiu para este artigo também o diálogo com a sociologia do militantismo ou das carreiras militantes (SWICKI; SIMÉANT, 2011), a qual se inspira fortemente no interacionismo simbólico, que já buscava superar as clássicas dicotomias estrutura versus sujeitos e diacronia versus sincronia, levando a considerar um mosaico de fatores que levam ao engajamento - não apenas os processos precedentes de socialização, mas também as redes de interações presentes (BRENER, 2014). O engajamento é visto, ele próprio, como processo e é preciso compreender a construção do sentido do compromisso por parte de militantes (FILLIEULE, 2015): não se nasce militante e algumas pessoas se tornam militantes dados contexto, circunstâncias e trajetórias pessoais, destacando-se disposições sociais, redes preexistentes e a moldura histórica dos processos políticos (SEIDL, 2014).

Lúcia de Castro tem proposto a noção de subjetivação política em oposição à de socialização política, junto à sua equipe (CASTRO, 2009, CASTRO; MATTOS, 2009, MAYORGA; CASTRO; PRADO, 2012), noção com a qual enfatiza dispositivos que jovens criam ou mobilizam para a construção de seu "eu" e de suas relações com a sociedade e as instituições políticas. São reconhecidos como importantes e necessários, não simplesmente patológicos, tensões e conflitos nesses processos, bem como os espaços não convencionais de participação política, incluindo a arte e a cultura.

Essa interpretação de Castro acerca da subjetivação política foi muito importante para a pesquisa anterior realizada pelo Grupo de Estudos sobre a Juventude, a qual tratou de coletivos juvenis em uma universidade pública. 
Ao acompanhar jovens da universidade que eram militantes ou ativistas em organizações políticas, pudemos observar esses sujeitos em momentos muito distintos: uma fase inicial de mobilização e atuação em uma ação coletiva, a greve estudantil e a ocupação de campus da universidade durante 57 dias; e uma fase posterior de desmobilização política.

$\mathrm{Na}$ fase inicial, a ocupação, em especial por meio da atuação destacada de estudantes independentes, demonstrou a força da noção de subjetivação política, valorizando os processos de autogestão e autoformação políticas durante a ação coletiva (GROPPO et al., 2017). Em contrapartida, no momento seguinte, quando se deu a desmobilização, ficou patente que os processos pregressos de socialização política, como descritos anteriormente, voltavam a ganhar relevo quando se tratava de compreender se e como tais estudantes continuavam a atuar politicamente (GROPPO et al., 2019).

Se, como conceitos, em suas abstração, socialização política e subjetivação política, parecem se opor, os dados empíricos, porém, levaram-nos a reconhecer as articulações entre dinâmicas de subjetivação política momentos imprevistos na trajetória dos sujeitos ou experiências contingentes - e o processo de socialização política longo, acumulativo e mais previsível. Isso foi necessário para buscar compreender o que os sujeitos faziam ou poderiam fazer, em suas trajetórias, com aquela experiência ímpar - a subjetivação política durante a ação coletiva dissensual. Passada tal ação, as implicações da socialização política voltavam a se fazer decisivas, mas nunca deterministas.

Entretanto, o reencontro com a concepção de subjetivação política pelo próprio Rancière (1996) vem nos alertar que não se trata simplesmente de subsumi-la à de socialização política. Rancière demonstra a importância dos momentos em que a ação coletiva - a "política" como dissenso - abala a ordem social e institucional constituída e ilumina novos campos do possível. Também, revela a permanência dessa experiência vivida pelas pessoas e coletivos como algo latente, possível de novas irrupções, mesmo após um largo período (RANCIĖRE, 1988).

Para Rancière (2010), a subjetivação política é, sobretudo, um processo de desidentificação, o qual rompe ou abala as funções sociais esperadas de quem, na normalidade da "ordem policial", associava sua função social a um status desigual no corpo da ordem social. As ocupações secundaristas, nesse sentido, poderiam ser interpretadas como possibilidade de ruptura, deslocamento ou modificação das funções e do status de adolescente e discente. Ocupas, ao liderarem ações coletivas e gerenciarem atividades formativas, contrapuseram-se às concepções usuais relativas a adolescentes e estudantes, concepções que as consideram pessoas em "desenvolvimento", portanto inferiores às adultas em capacidade de organização e condução de processos educacionais e políticos.

Esse caminho também nos é indicado pela análise de Rossana Reguillo (2013) sobre o movimento juvenil mexicano \#YoSoy132, definido como dissidência, não por trazer discordância, oposição ou tentativa de transformar o sistema a partir de dentro, mas por seu sentido de separação, intenção de não compartilhar e desejo de vivências apartadas do sistema. A dissidência articula resistência, sedução e imaginação quando suas ideias e ações se deslocam das representações dominantes sobre o real. Ela é, portanto, pré-figurativa, pois anuncia outro real nas suas próprias práticas dissidentes. Constitui novo terreno criador de outras subjetividades.

A seguir, buscamos analisar como ocupas de MG retém ou reelaboram a experiência de ocupar, para o que a noção de subjetivação política de Rancière será muito importante, tanto quanto a de socialização política. Elas ajudam a compreender o que sujeitos e organizações políticas fazem, ou podem fazer, a posteriori, com a experiência de uma ação coletiva.

\section{A Experiência de Ocupar}

A maioria das catorze entrevistas semiestruturadas em MG foram feitas no sul de Minas: sete em Poços de Caldas e três em um pequeno município. Duas foram realizadas na capital Belo Horizonte (BH), localizada 
na região central do estado, e outras duas foram feitas em Juiz de Fora, na Zona da Mata. Conforme apresentado ao Comitê de Ética de Pesquisa com Seres Humanos, para preservar as pessoas entrevistadas, elas escolheram pseudônimos e os nomes das escolas não serão citados, bem como o nome do pequeno município do sul de MG. As entrevistas não tiveram a intenção de constituir um panorama exaustivo das ocupações em MG. Buscamos, antes, analisar a diversidade dos sujeitos e das suas formas de participação. Privilegiamos as mulheres, que atuaram nas ocupações em maior número e com mais destaque: nove mulheres contra cinco homens.

Os dados da Tabela 1 já demonstram que a relação de ocupas com a política compõe um cenário de inusitada complexidade. No momento da ocupação, onze estudantes eram independentes e três, militantes, considerando a militância política stricto sensu (ou seja, na condição de membro engajado formalmente em organizações políticas, como entidades do movimento estudantil, juventudes partidárias e partidos). As três pessoas militantes pertenciam à União da Juventude Socialista (UJS), que tem forte relação com o Partido Comunista do Brasil (PCdoB) e, há vários anos, tem hegemonizado a União Nacional dos Estudantes (UNE) e a União Brasileira dos Estudantes Secundaristas (UBES).

Ocupar, em um primeiro momento, parece ter estimulado o engajamento militante, já que, de dez independentes, quatro ao menos experimentaram militar no Levante Popular da Juventude (LPJ). A LPJ, organização de juventude com fortes vínculos com o partido não eleitoral Consulta Popular, tem demonstrado grande capacidade de atrair jovens, aglutinando práticas culturais inovadoras e militância clássica, assim como pautas identitárias e socialistas. Contudo, apenas Pagu continuava no LPJ quando entrevistada, enquanto Have ingressara na Juventude do Partido dos Trabalhadores (JPT).

Quando da realização das entrevistas, apenas quatro pessoas mantinham a militância. É preciso recordar, entretanto, que o próprio cenário político passou a ser cada vez mais desfavorável para a sobrevivência dessas organizações, em especial nas regiões mais distantes das capitais e dos grandes centros urbanos. Se a persistente Kahlo continuava a atuar intensamente pelo sindicato hoteleiro, mesmo sem cargo na organização, Nakas diz que o LPJ, de cujas reuniões chegou a participar, havia se desmobilizado muito em sua cidade. O contexto político desfavorável, mais do que a falta de disposição pessoal, talvez explique o dilema que ela coloca:

A gente batalhou tanto, foi tão difícil, a gente sem embasamento nenhum [...] pra brigar com essas pessoas [...]. Aí depois, no final, [...] cada um foi para um lado, não tinha força para fazer realmente o que tinha proposto fazer na escola (Nakas).

Mais marcantes entre independentes, mas também presente na ex-militante Elionor, foram os relatos que indicaram conversão das experiências políticas vividas na ocupação em uma distinta atuação na vida pessoal e no cotidiano (trabalho, educação e cultura). Estão presentes em Carolina de Jesus - contra o assédio no seu ambiente de trabalho e na defesa da diversidade em favor da sua família - e nas apostas de Raven, Nakas, Cássia Eller e Elionor na educação e nas artes (em especial o teatro). Os relatos por vezes verbalizam a esperança de uma transformação social mais lenta, a longo prazo, de baixo para cima, a partir do cotidiano:

Depois da ocupação, a gente não quis fazer nada, por causas das ameaças. [...] Eu e a Maria, que fomos as lideranças para quem sempre teve muitos olhos e ameaças; a gente quis recuar. [...] Se a gente quer mudança, a gente vai conseguir só ao longo do tempo, porque não foi do nada que a gente conseguiu o que a gente tem hoje. Não vai dar não, a gente vai conseguir mais aos poucos. Eu trabalho isso no meu serviço, na minha vida, com a minha irmã, com a minha família, e passo para as pessoas [...] esse movimento de querer mudar, de querer evoluir, melhorar para o nosso país (Carolina de Jesus). 
Tabela 1. Caracterização de ocupas de MG em 2016 que concederam entrevistas.

\begin{tabular}{|c|c|c|c|c|c|c|}
\hline Pseudônimo & Gênero & Idade & Raça/cor & Escola ocupada & Atuação política & Atuação na ocupação \\
\hline Ana Clara & $\mathrm{F}$ & 18 & Branca & $\begin{array}{l}\text { Escola de } \\
\text { Aplicação, Juiz } \\
\text { de Fora. }\end{array}$ & $\begin{array}{l}\text { Era filiada à UJS, } \\
\text { na qual se mantém. } \\
\text { Filiou-se ao PCdoB. }\end{array}$ & $\begin{array}{l}\text { Ocupou escola da qual } \\
\text { não era estudante, } \\
\text { como tarefa para a } \\
\text { UJS, atuando em várias } \\
\text { comissões. }\end{array}$ \\
\hline Ramon & $\mathrm{M}$ & 23 & Branca & $\begin{array}{l}\text { Instituto Técnico, } \\
\text { Juiz de Fora. }\end{array}$ & $\begin{array}{l}\text { Liderança da UJS. } \\
\text { Atual coordenador } \\
\text { geral de Diretório } \\
\text { Central de } \\
\text { universidade pública e } \\
\text { filiado ao PCdoB. }\end{array}$ & $\begin{array}{l}\text { Era da diretoria do } \\
\text { grêmio, que organizou a } \\
\text { ocupação, orientada por } \\
\text { UJS e UBES. }\end{array}$ \\
\hline Pagu & $\mathrm{F}$ & 18 & Branca & $\begin{array}{l}\text { Escola Municipal } \\
\text { Central, Poços de } \\
\text { Caldas. }\end{array}$ & $\begin{array}{l}\text { Passou a militar, por } \\
\text { influência da ocupação, } \\
\text { no Levante Popular } \\
\text { da Juventude (LPJ), } \\
\text { em coletivo feminista } \\
\text { e no Partido dos } \\
\text { Trabalhadores (PT). }\end{array}$ & $\begin{array}{l}\text { Atuou em todas as } \\
\text { comissões, desde o início } \\
\text { da ocupação. }\end{array}$ \\
\hline Have & M & 20 & Negra & $\begin{array}{l}\text { Escola Estadual } \\
\text { Periférica e } \\
\text { Escola Estadual } \\
\text { Central, Poços de } \\
\text { Caldas. }\end{array}$ & $\begin{array}{l}\text { Sem militância prévia, } \\
\text { ingressou na Juventude } \\
\text { do PT (JPT), mas tem } \\
\text { se afastado para se } \\
\text { dedicar à graduação. }\end{array}$ & $\begin{array}{l}\text { Era da direção do } \\
\text { grêmio, que organizou a } \\
\text { ocupação de sua escola. } \\
\text { Também participou da } \\
\text { ocupação de outra escola } \\
\text { e da Superintendência } \\
\text { Regional de Ensino } \\
\text { (SRE). }\end{array}$ \\
\hline Elionor & $\mathrm{F}$ & 18 & Branca & $\begin{array}{l}\text { Escola Estadual } \\
\text { Central, Belo } \\
\text { Horizonte. }\end{array}$ & $\begin{array}{l}\text { Militante da UJS, } \\
\text { participava da direção } \\
\text { do grêmio, da qual } \\
\text { seria sua presidente } \\
\text { em 2017. Abdicou } \\
\text { da presidência e } \\
\text { desfiliou-se da UJS. }\end{array}$ & $\begin{array}{l}\text { Era da direção do } \\
\text { grêmio, que organizou a } \\
\text { ocupação. Coordenou as } \\
\text { oficinas e a comissão de } \\
\text { comunicação. }\end{array}$ \\
\hline Humberto & $\mathrm{M}$ & 20 & Negra & $\begin{array}{l}\text { Escola Estadual } \\
\text { Periférica, sul de } \\
\text { MG. }\end{array}$ & $\begin{array}{l}\text { Atuante da Pastoral } \\
\text { da Juventude (PJ), da } \\
\text { qual ainda participava. } \\
\text { Era coordenador do } \\
\text { grêmio. }\end{array}$ & $\begin{array}{l}\text { Era coordenador do } \\
\text { grêmio, que organizou a } \\
\text { ocupação da escola. }\end{array}$ \\
\hline $\begin{array}{l}\text { Carolina de } \\
\text { Jesus }\end{array}$ & $\mathrm{F}$ & 19 & Branca & $\begin{array}{l}\text { Escola Estadual } \\
\text { Central, Poços de } \\
\text { Caldas. }\end{array}$ & $\begin{array}{l}\text { Sem militância prévia } \\
\text { ou posterior. Era da } \\
\text { direção do grêmio. }\end{array}$ & $\begin{array}{l}\text { Era da direção do } \\
\text { grêmio, que organizou } \\
\text { a ocupação. Também } \\
\text { ocupou a SRE. }\end{array}$ \\
\hline Beatriz & $\mathrm{F}$ & 19 & Negra & $\begin{array}{l}\text { Escola Estadual } \\
\text { Central, Poços de } \\
\text { Caldas. }\end{array}$ & $\begin{array}{l}\text { Sem militância prévia. } \\
\text { Formou coletivo que } \\
\text { criou aplicativo de } \\
\text { celular para mulheres } \\
\text { denunciarem violência. }\end{array}$ & $\begin{array}{l}\text { Atuou nas comissões de } \\
\text { limpeza e alimentação. } \\
\text { Participou de todas as } \\
\text { oficinas }\end{array}$ \\
\hline
\end{tabular}


Tabela 1. Continuação...

\begin{tabular}{|c|c|c|c|c|c|c|}
\hline Pseudônimo & Gênero & Idade & Raça/cor & Escola ocupada & Atuação política & Atuação na ocupação \\
\hline Nakas & $\mathrm{F}$ & 20 & Branca & $\begin{array}{l}\text { Escola Municipal } \\
\text { Central, Poços de } \\
\text { Caldas. }\end{array}$ & $\begin{array}{l}\text { Sem militância prévia } \\
\text { ou posterior. }\end{array}$ & $\begin{array}{l}\text { Inseriu-se depois de } \\
\text { iniciada a ocupação e } \\
\text { participou da comissão } \\
\text { de segurança e } \\
\text { alimentação, bem como } \\
\text { da ocupaça da SRE. }\end{array}$ \\
\hline Johnny Cash & $\mathrm{M}$ & 21 & Negra & $\begin{array}{l}\text { Escola Estadual } \\
\text { Central, Poços de } \\
\text { Caldas. }\end{array}$ & $\begin{array}{l}\text { Sem militância prévia. } \\
\text { Participou por algumas } \\
\text { semanas do LPJ. Não } \\
\text { tem mais intenção de } \\
\text { militar. Foi o único a } \\
\text { declarar ter votado no } \\
\text { presidente eleito em } \\
2018 \text {. }\end{array}$ & $\begin{array}{l}\text { Ocupou escola da qual } \\
\text { não era estudante, em } \\
\text { apoio a amigas. Atuou } \\
\text { em várias comissões e da } \\
\text { ocupação da SRE. }\end{array}$ \\
\hline Khalo & $\mathrm{F}$ & 21 & Branca & $\begin{array}{l}\text { Escola Estadual } \\
\text { Central, Poços de } \\
\text { Caldas. }\end{array}$ & $\begin{array}{l}\text { Sem militância prévia, } \\
\text { participou por alguns } \\
\text { meses do LPJ e hoje } \\
\text { apoia o movimento } \\
\text { sindical do ramo da } \\
\text { hotelaria, mas sem } \\
\text { cargo no sindicato. }\end{array}$ & $\begin{array}{l}\text { Começou a participar } \\
\text { depois de a ocupação } \\
\text { ter se iniciado, atuou } \\
\text { em comunicação e } \\
\text { intercâmbio, além das } \\
\text { oficinas e da criação de } \\
\text { horta na escola. Ocupou } \\
\text { a SRE. }\end{array}$ \\
\hline Raven & M & 22 & Parda & $\begin{array}{l}\text { Escola Estadual } \\
\text { Periférica, sul de } \\
\text { MG. }\end{array}$ & $\begin{array}{l}\text { Sem militância prévia } \\
\text { ou posterior. Diz que } \\
\text { poderia se engajar em } \\
\text { movimento pela causa } \\
\text { LGBTT }^{2} \text {. }\end{array}$ & $\begin{array}{l}\text { Entrou na ocupação } \\
\text { depois de seu início, } \\
\text { atuando intensamente } \\
\text { nela. Participou de } \\
\text { manifestação em } 29 \text { de } \\
\text { novembro de } 2016 \text { em } \\
\text { Brasília. }\end{array}$ \\
\hline Gabriela & $\mathrm{F}$ & 19 & Branca & $\begin{array}{l}\text { Escola Estadual } \\
\text { Central, sul de } \\
\text { MG. }\end{array}$ & $\begin{array}{l}\text { Antes da ocupação, } \\
\text { aproximara-se de } \\
\text { juventude partidária } \\
\text { que ocupava uma } \\
\text { universidade. } \\
\text { Atualmente, manifesta } \\
\text { rejeição por juventudes } \\
\text { partidárias. }\end{array}$ & $\begin{array}{l}\text { Independente, ajudou a } \\
\text { organizar a ocupação de } \\
\text { sua escola, que não tinha } \\
\text { grêmio. Tendo entrado } \\
\text { em embate com a JPT, } \\
\text { retirou-se antes do final } \\
\text { da ocupação. }\end{array}$ \\
\hline Cássia Eller & $\mathrm{F}$ & 19 & Branca & $\begin{array}{l}\text { Escola Estadual } \\
\text { Central, Belo } \\
\text { Horizonte. }\end{array}$ & $\begin{array}{l}\text { Sem militância prévia } \\
\text { ou posterior. Atuação } \\
\text { em paróquia católica } \\
\text { e projeto social, com } \\
\text { teatro. }\end{array}$ & $\begin{array}{l}\text { Independente, ajudou a } \\
\text { organizar a ocupação de } \\
\text { sua escola, que não tinha } \\
\text { grêmio. }\end{array}$ \\
\hline
\end{tabular}

Fonte: Dados das pesquisas "Ocupações secundaristas no Brasil em 2015 e 2016" e "Ocupações Secundaristas no Sul de Minas e o Conceito de Educação Menor". 
No trecho a seguir, Elionor $(\mathrm{BH})$ indica que a ressignificação de sua militância também tem causas subjetivas importantes: a atuação pela arte é a que tinha para ela realmente sentido pessoal:

Como eu posso mudar as coisas para as outras pessoas se eu não estava conseguindo viver a minha vida? E eu acho que a arte é esse lugar que tem essa capacidade de sensibilizar, tocar as pessoas, inclusive politicamente. [...] Eu vejo o que uma oficina muda para os meninos de escola de periferia. O que isso faz na vida das pessoas é muito grande, para mim é maior que ser uma vereadora que vai falar no microfone. [...] A política às vezes vem com um poder muito sujo, e eu não estou disposta a comprar essa briga (Elionor).

Johnny Cash é autor da trajetória política mais elíptica. Após a ocupação, chegou a militar por pouco tempo na LPJ, mas "minha cabeça foi mudando e eu virei extrema direita, aí eu votei nele, e passou mais um tempo e minha cabeça já mudou de novo". Já Gabriela é autora do relato mais desencantado com a política, tanto pela derrota do movimento, quanto pelo enorme grau de tensão que viveu na ocupação de sua escola, fosse pelas ameaças vindas de algozes, fosse pelos desentendimentos grupo de estudantes independentes que iniciou a ocupação e a JPT.

Apenas duas pessoas entrevistadas negaram que a ocupação tenha sido uma experiência de influência grande e positiva em suas trajetórias pessoais: Sandro e Gabriela. Sandro considerou que o episódio teve pouca importância para sua formação política. Era o mais velho entre as pessoas entrevistadas (23 anos) e era já relativamente experimentado na militância em uma juventude partidária, a UJS, que valoriza a organização em detrimento da ação direta e independente. Já Gabriela considerou a experiência apenas negativa para sua trajetória, o que a levou a se desinteressar pela política. Entretanto, seu caso é ambíguo, já que, ao fim da entrevista, ela recordou a empolgação no início da ação e reconhece que a experiência influenciou sua decisão de ser professora.

As outras doze pessoas consideram a experiência de ocupar fortemente importante, bem como se consideram muito afetadas por ela. Mesmo as duas pessoas que eram militantes da UJS durante a ação coletiva, Bianca e Elionor, reconhecem esse fato, já que viveram o processo de engajamento na organização com a ocupação. Para duas pessoas, ao menos até a entrevista, ocupar parece ter sido a principal experiência de suas vidas: "Melhor experiência da minha vida, tudo que passei lá dentro me fez ver o Raven como pessoa" (Raven); "Foi a época em que eu me senti mais viva" (Nakas).

Selecionando, nas entrevistas, o que nos pareceram as vivências mais marcantes durante a ocupação, consideramos que podem ser traduzidas, principalmente, como aprendizados. Desse modo, encontramos os seguintes aprendizados, em ordem da frequência com que foram citados:

- Concepção de educação: diferentes formas de ensino-aprendizagem e conteúdos alternativos ensinados durante a ocupação. Duas ocupas destacam, inclusive, aprender a cozinhar e lavar banheiro. Também citam, após a ocupação, algumas mudanças na escola, que se tornou mais democrática ou adotou algumas vivências educacionais alternativas (como as carteiras em círculo), além da valorização docente;

- Influência na decisão de cursar a educação superior (ES) e no tipo de carreira. Onze ocupas, inclusive dois que ainda não haviam ingressado na ES, reconheceram essa influência. Durante as entrevistas, dez ocupas estavam na ES e uma havia evadido por causa do trabalho. Seis estudavam em IES públicas. O contato com militantes que eram estudantes da ES favoreceu muito o conhecimento dos processos de seleção e as possibilidades de cursar IES públicas e 
privadas. Alguns relatos falam da influência para procurar dada carreira, pelo reconhecimento das dimensões social e política das profissões, com a experiência da ocupação. Outros tratam do contato com profissionais de psicologia que foram ministrar oficina nas escolas;

- Capacidade de crítica e autocrítica. Vários relatos trataram da abertura de si ao mundo, da quebra de preconceitos e do desenvolvimento do pensamento crítico;

- Esforço para dialogar com outros sujeitos, como estudantes que não eram ocupas, docentes e comunidade. Os relatos tratam de assembleias, aulões, oficinas abertas e divulgação de atividades pelas redes sociais, buscando esclarecer os motivos da ocupação e demonstrar que estavam ocorrendo ações educacionais na escola ocupada - mesmo que nem sempre tenham sido eficazes;

- Descoberta ou clareza sobre a orientação sexual não heteronormativa. Quatro ocupas citaram que a participação no movimento foi importante para definirem sua condição como não heteronormativa: Elionor como pansexual; Kahlo como lésbica; Johnny Cash como "sem definição"; e Raven compreendendo melhor sua homossexualidade;

- Solidariedade e coletivismo. Relatos se referem à descoberta da importância do trabalho coletivo, do apoio mútuo e da capacidade de gerir, de modo solidário, a ocupação;

- Perceber-se como parte de um movimento maior, em âmbito nacional.

\section{Família, Engajamento e Forma de Participação na Ocupação}

Podemos separar as pessoas entrevistadas em quatro grupos para analisar a relação entre a sua forma de participação na ocupação e as influências de suas famílias de origem: 1) militantes; 2) lideranças; 3) presentes desde o início da ocupação; 4) ingressantes posteriores na ocupação. Para a análise das famílias, consideramos dados informados sobre renda familiar, escolaridade de responsáveis e influência da família na formação política.

1. Militantes: as três pessoas que militavam na UJS antes e durante a ocupação parecem referendar teses clássicas sobre a socialização política, já que encontramos em suas famílias a posse de capitais que parecem facilitar o engajamento - tanto o capital econômico (Sandro) quanto o capital cultural ${ }^{3}$ (Ana Paula e Elionor). Ocuparam escolas em que a UJS e a UBES, assim como outras juventudes partidárias e entidades estudantis rivais, parecem ter tradicionalmente investido e atuado, instituições de Ensino Médio públicas prestigiosas, como trataremos melhor adiante - locais onde são mais corriqueiras as ofertas para o engajamento militante;

2. Lideranças: apenas Sandro era militante entre as seis lideranças de ocupação entrevistadas. As demais eram independentes: Gabriela, Humberto, Carolina de Jesus, Cássia Eller e Have. A condição de liderança, porém, guarda pouca correlação com o capital cultural da família: a rigor, apenas se enquadra o caso de Cássia Eller, com mãe advogada, que auxiliou juridicamente na ocupação de sua filha, e pai ator, que já fora candidato à vereança. Quanto ao capital econômico, apenas se enquadra o caso de Gabriela, cuja família tinha a maior renda entre as catorze pessoas. A condição de liderança guarda mais relação com a experiência política prévia, especialmente a participação na direção do grêmio estudantil: casos de Sandro, Humberto, Have e Carolina 
de Jesus. A se considerarem os dados acerca de renda, escolaridade de responsáveis, interesse da família por política e experiência política prévia, dentro das interpretações mais tradicionais acerca da socialização política, a condição de liderança de Carolina de Jesus e Have seria muto improvável. Por outro lado, as famílias de Gabriela, Cássia Eller e Humberto já lhes tinham despertado algum interesse pela política.

3. Presentes desde o início da ocupação: de oito ocupas que não exerceram funções de liderança, três participaram desde o seu início. Contam-se aqui Elionor, que estava sendo preparada para ser a próxima presidente do grêmio, ao lado de Pagu e Beatriz, de famílias de classe média baixa e que continuam na militância (Pagu, na LPJ) ou no ativismo (Beatriz com o aplicativo de defesa das mulheres). O relato de Pagu registra o envolvimento seu e de sua família em atividades da Igreja Católica, que parecem ter se convertido, no seu caso, em dedicação à militância.

4. Ingressantes posteriores na ocupação: aqui se contam cinco ocupas que, exceto no caso de Bianca, tinham pouca herança familiar nas formas de capital econômico, capital cultural e formação política. Johnny Cash, estudante de escola periférica, sem qualquer tipo de participação política prévia, com mãe empregada doméstica e Ensino Fundamental incompleto, ocupou outra escola que não a sua, mas não como tarefa militante - ele passava em frente à escola e quis ajudar suas amigas, lideranças da ocupação. Raven, Nakas e Kahlo ocuparam suas próprias escolas - após conversar com ocupas sobre os motivos da ação, interessaram-se em ajudar. Raven, estudante da Educação de Jovens e Adultos (EJA), e Kahlo vinham também de famílias de baixa renda, enquanto Nakas vinha de família de classe média baixa.

\section{Tipos de Ocupação}

Podemos classificar as escolas ocupadas em MG, pelo tipo de interesse desperto nas organizações políticas, em 3 tipos: 1) escolas periféricas; 2) escolas centrais; 3 ) escolas prestigiosas.

1. Escolas periféricas: das catorze pessoas entrevistadas, apenas três estudavam em escolas não centrais ou de bairros não considerados de classe média, as quais chamaremos aqui escolas periféricas: Humberto, Raven e Have. Estudantes tomaram a decisão de ocupar por conta própria, por vezes de forma vanguardista, como ocorreu na escola periférica de Humberto e Raven, ocupada antes das escolas centrais e da própria universidade pública do pequeno município sul-mineiro. Have ajudou a ocupar escola central em Poços de Caldas antes de levar a proposta para a sua própria escola. Esses casos indicam o protagonismo e a autonomia das escolas periféricas, bem como capacidade ou interesse baixos das organizações políticas de recrutarem tais ocupas, ainda que, na escola periférica de Humberto e Raven, tenha havido relevante apoio de estudantes da universidade e de sindicato docente - o que não foi suficiente, no entanto, para evitar a falta de alimentos em dado momento, conforme narra Raven;

2. Escolas centrais: a primeira escola ocupada em Poços de Caldas, estadual e central, é bom exemplo das formas que, nas escolas não periféricas - que chamaremos aqui centrais -, as relações entre ocupas e organizações políticas assumiram. Esse caso se assemelha aos das escolas de Pagu (colégio municipal de Poços de Caldas) e Cássia Eller (escola em bairro de classe média de $\mathrm{BH}$ ). Houve processo mais ou menos longo de preparação da ocupação, com a participação de militantes de juventudes partidárias e profissionais de Direito de sindicatos 
ligados à educação, na formação política, na organização, nas negociações com o poder público e em orientações jurídicas. Segundo Nakas (colégio municipal de Poços de Caldas), "era um tanto de jovem sem conhecimento de política, fazendo um ato completamente político. [...] Vocês militantes chegaram e deram o norte, falaram: 'vocês não podem fazer isso, vocês podem fazer isso.' Então, isso ajudou a gente a tomar as decisões [...]”.

Carolina de Jesus reconhece a importância desse apoio, mas faz questão de afirmar a autonomia da ocupação, inclusive porque o grêmio convidou estudantes de outras escolas, que haviam conhecido em atividade formativa promovida pela própria Secretaria Estadual de Educação, para ser ocupas. Ao fim, ocupas eram uma espécie de coalizão entre estudantes da própria escola, estudantes de outras escolas, que receberam convite ou se convidaram, e militantes de entidades estudantis e juventudes partidárias. Os relatos nessas escolas tendem a valorizar a autonomia de ocupas, mas reconhecem a importância do apoio das organizações, ainda que às vezes a convivência não tenha sido tranquila, como afirma o relato de Cássia Eller a respeito de militantes de duas entidades estudantis rivais:

Eu percebi que eles digladiavam muito entre si [...] e fugiam do propósito. Era mais importante tal instituição estudantil ter mais verba, e a outra ficava com raiva, e aí tratavam as escolas como mera escola de cabeça de boi. Instituía o grêmio dentro da escola, então esta escola é nossa. [...] Não era dos alunos (Cássia Eller).

3. Escolas prestigiosas: um terceiro tipo de ocupação foi o que se deu tanto na escola de Elionor (em região central de $\mathrm{BH}$ ) quanto nas escolas de Juiz de Fora (o instituto técnico e a escola de aplicação). Segundo relatos, foram ações feitas pelos grêmios com orientação de uma entidade estudantil em particular - nesses casos, a UBES, hegemonizada pela UJS. Trata-se justamente da situação que Cássia Eller desejava evitar em sua escola. Instituições consideradas tradicionais ou afamadas em grandes cidades, como essas três escolas, tenderam a ter esse tipo de ocupação organizada e orientada mais diretamente por militantes das entidades estudantis. Diferentemente dos demais tipos de ocupação, em que se enfatizou a importância (relativa ou absoluta) da autonomia de ocupas, a tendência aqui foi valorizar a "importância de se organizar", conforme o relato de Sandro: "participar e se organizar dentro dessas entidades é muito importante. Também não só em nível local, mas em níveis maiores, como UNE e UBES” (Sandro, Juiz de Fora).

Uma organização da JPT quis fazer algo semelhante na escola estadual mais tradicional de pequeno município do sul de MG. Nessa escola, sem grêmio atuante, Gabriela, ao lado de mais três estudantes, planejou a ocupação com o apoio de estudantes que já ocupavam a universidade pública da cidade. Depois de iniciada a ocupação, liderada por independentes, a JPT migrou para lá a sua militância, outrora ocupante da universidade. A JPT passou a controlar a ocupação, para a frustração de Gabriela que, após vários conflitos, abandonou a ocupação - a qual viria a ter um desfecho bastante violento, por sinal.

A comissão de ocupação estava caindo no papo deles: "Eles ocuparam a universidade, eles têm mais experiência do que a gente, os caras estão na militância há mais tempo.” [...] Eles influenciaram muita gente ali dentro. Tanto que eles tiraram muita ovelhinha dali para o coletivo, muita gente que não sabia de nada e depois das ocupações entrou para o coletivo (Gabriela). 
Esses três tipos de ocupação registrados em MG demonstram a complexidade das relações vividas entre estudantes e juventudes partidárias ou entidades estudantis. Analisar esse aspecto é um dos objetivos do próximo item.

\section{Alter-ativismo e Subjetivação Política}

A rigor, apenas o militante Sandro teve pequena influência da experiência de ocupar em sua formação política. Sua trajetória política já estava bem-estabelecida na UJS e no PCdoB. Para as demais pessoas, a experiência das ocupações foi impactante e suscitou a prática ou o ensaio, ao lado de formas educacionais alternativas, de outras formas de fazer e viver a política, formas essas que têm sido anunciadas, algumas vezes, como avessas ou opostas à militância clássica nas organizações formais. Junho de 2013 é tratado como grande exemplo dessa oposição.

A princípio, Bringel e Pleyers (2015, p. 14) parecem referendar essa ideia, ao tratar das reconfigurações do ativismo no Brasil e no mundo, constituindo o que chamam "alter-ativismo": sujeitos e organizações mais descentradas; mobilizações menos controladas por organizações, com difusão e reprodução viral e maior espaço para o indivíduo; deslocamento das organizações centrais de outrora (sindicatos, partidos e certos movimentos sociais, principalmente o estudantil) "como instâncias centrais da socialização militante"; deslocamento de processos de engajamento militante, "com destaque para a inserção em pequenas coletividades, redes e grupos de afinidades"; papel destacado das novas tecnologias para contrainformação, permitindo interação e difusão menos mediada por organizações; e maior aproximação da participação política à vida cotidiana. As práticas e as expressões desses sujeitos emergentes buscam se distanciar da formapartido e da forma-movimento, bem como de repertórios de mobilização com bandeiras e lemas definidos prévia e externamente, puxados por carros de som e vozes únicas. Procuram também negar as lideranças formais (mesmo quando elas existem informalmente).

Entretanto, os autores anunciam que o alter-ativismo não está necessariamente apartado das sociedades política e civil. Pelo contrário: temos a coexistência entre elas, com a possibilidade tanto da cooperação quanto do conflito (BRINGEL; PLEYERS, 2015, p. 15-16). Nossa pesquisa tem justamente flagrado que, no movimento das ocupações, a principal tendência foi de que ativistas recebessem a colaboração, $o$ apoio e até a atuação lado a lado de militantes daquelas organizações políticas clássicas. Em todo o país, especialmente nas escolas não periféricas, são inúmeros os exemplos de cooperação, inclusive durante o processo mais silencioso de preparação das ocupações. Mesmo as escolas periféricas tiveram algum apoio, em especial quando tinham alguma proximidade ou relação com universidades públicas. Contudo, isso não impediu que houvesse casos de cooptação e de conflito, como narramos anteriormente.

Por outro lado, observamos pequeno engajamento militante de ocupas nas organizações partidárias e nas entidades estudantis. Limitação similar já havia sido observada em estudantes da educação superior que vinham das classes populares em instituições interioranas (GROPPO et al., 2019). A dificuldade se explica não apenas pela desconfiança generalizada que vem se nutrindo pelas organizações políticas tradicionais, mas também pelo cenário político bem mais avesso às organizações da esquerda e aos movimentos sociais progressistas. Esse cenário já se anunciava com o aumento da repressão às ocupações estudantis no segundo semestre de 2016 e a violência policial contra a manifestação de 29 de novembro em Brasília, na votação em primeiro turno pelo Senado da PEC n. 55. Na verdade, a manifestação em Brasília é outro importante exemplo da coalizão entre o ativismo de ocupas independentes e as organizações políticas e sindicais da esquerda o primeiro fornecendo manifestantes entusiastas; as segundas, transporte, alimentação e apoio logístico. 
Outra forma de analisar a especificidade do agir político na ocupação, em vez de classificá-lo como um ou outro estilo de ativismo, é tratar a experiência como processo de subjetivação política. Para tanto, podemos contrastar essa noção com o que Muxel afirma ser o objetivo dos estudos sobre a socialização política: “compreender o modo como se formavam as identidades políticas dos indivíduos"; ou seja, responder à questão: "como se forjavam os valores, as convicções, as opiniões que poderiam constituir a identidade profunda, as crenças e o sistema de valores dos indivíduos?” (MUXEL apud TOMIZAKI; DANILIAUSKAS, 2018, p. 348). Ao se considerar que a subjetivação política é um processo de desidentificação, é possível dizer que, quando ela ocorre, durante momentos da política como dissenso, as identidades políticas, assim como outras identidades sociais, são rompidas, ainda que provisoriamente. No caso de uma ação coletiva protagonizada por adolescentes, trata-se principalmente de rasurar ou revirar a disposição política socialmente esperada do sujeito; ou seja, a identidade política que provavelmente iria se construir de acordo com sua posição e suas funções sociais.

Para Rancière, a subjetivação política é um momento de suspensão da identidade política, assim como de outras identidades sociais - etária (adolescente), ocupacional (estudante), de gênero, étnica, de orientação sexual, entre outras -, que podem ser ressignificadas ou rompidas durante a ação política, mas não necessariamente implicam a fixação de novas identidades estáveis. Ocupas em MG que entrevistamos relataram grande influência do movimento na recomposição da identidade estudantil (o projeto de cursar a ES) e da identidade sexual (como a afirmação da não heteronormatividade). No entanto, o mesmo não se deu com as identidades políticas: há pequeno trânsito de ocupas para a militância partidária; independentes encontram poucos espaços e oportunidades para continuar a se expressar politicamente e essa identidade vai se enfraquecendo; e militantes tendem a se impactar menos pelo processo de subjetivação política, valorizando pouco o estilo alter-ativista que marcou o movimento. Nas simpatias eleitorais, entretanto, há mais efeito, considerando-se que apenas um ex-ocupa votou no candidato da extrema direita nas eleições presidenciais de 2018. As demais pessoas votaram em candidatos da esquerda ou da centro-esquerda em ambos os turnos das mesmas eleições, em grande contraste com as tendências gerais de voto nas regiões de MG onde moravam - largamente favoráveis ao candidato vencedor.

Isso nos leva a concluir que o termo "ocupa" não constitui identidade política, tampouco forja novas identidades políticas. Foi uma alcunha que ajudou a expressar as subjetivações políticas durante as ações coletivas subjetivações essas que apontam para diversas direções. Uma delas vai ao encontro da definição usada por Reguillo (2013) para caracterizar os movimentos juvenis que ela pesquisava: dissidência como pôr-se à parte, colocar-se fora do sistema e ensaiar, em um espaço físico e virtual ocupado, outras relações sociais e políticas (a pré-figuração). Isso é verdade apenas em parte no movimento das ocupações, considerando-se que ativistas estabeleceram intensas relações com organizações políticas, buscaram diálogo com estudantes que eram contra a ação e com a sociedade e até mesmo negociaram com governos. Todavia, é muito verídico quando se considera que as ocupações se fizeram como territórios à parte, para experimentações políticas e, principalmente, educacionais.

Encontramos, nas entrevistas, relatos que falam do reconhecimento da própria voz e da capacidade de agir contra o dano. Eles parecem tão fortes quanto as falas em que Raven e Nakas identificaram a ocupação como o momento, até então, mais pleno de suas vidas.

O adolescente mostrou que ele tem voz. [...] Foi bom porque eles sentiram o poder do adolescente. [...] Antes de ocupar, ninguém botava fé na gente. [...] Eu falei que não é porque a gente não tinha conseguido tudo o que a gente queria, que a gente não tinha vencido. Eu falei pra eles: "Gente, olha o tanto de coisas que vocês conquistaram! Vocês ocuparam uma escola, ocuparam a Superintendência, vocês mudaram a cabeça de um monte de gente." [...] Foi uma vitória muito grande, porque eu entrei lá nem sabendo o que estava fazendo, e olha o jeito que eu saí (Johnny Cash, Poços de Caldas). 
Uma das principais coisas que moveram a juventude em 2016 [...] foi essa consciência de que a transformação teria que partir da gente. [...] A gente é a cara da transformação da educação, porque eu não acredito na educação que eu recebi na minha escola. E eu estudei em uma escola boa, era uma das melhores escolas de Belo Horizonte. [...] Eu acredito que ela tem que ser transformada. Então, a gente vai lá e dá a cara a tapa e fala: "Eu sou um estudante e eu posso mudar o espaço onde eu estou, porque é o meu direito" (Elionor, BH).

Pela primeira vez, me senti como se eu pudesse fazer alguma coisa: eu podia fazer aquilo ou eu podia não fazer, e eu escolhi fazer. Eu me senti lesado [...] e eu me vi na obrigação mesmo de fazer aquilo pra lutar por aquilo que era meu. [...] Uma questão que surgiu através dessas manifestações foi de que os alunos também têm voz [...] Isso veio pra mostrar que a gente pode igualar todos, que não existe essa hierarquia, que do mesmo jeito que um professor, diretor, supervisor, tem poder de voz dentro da escola, por outro lado o aluno também tem. [...] Serviu pra igualar e mostrar para os alunos, lógico que cada um dentro do seu limite, que tem o seu poder de voz e seu direito ali, que muitas vezes era lesado e a gente nem percebia (Humberto, pequeno município do sul de Minas).

[Eu] [m] reconheci como pessoa, como ser. [...] Me descobri como preto, pobre, viado, como uma pessoa fodida na sociedade, fora de qualquer padrão. E, através disso, eu vi que eu sou invisível não só para o Estado, mas para qualquer pessoa. Eu só existo quando eu incomodo e, a partir daquele momento, eu comecei a incomodar, porque eu comecei a falar que eu existo. [...]. Ocupar é um ato político muito forte, muito agressivo [...] e é nesse momento que a gente se afirma para o Estado: "Ei, não somos invisíveis. Somos pessoas visíveis e exigimos visibilidade, exigimos políticas públicas queremos que nos reconheçam como pessoas e estudantes" (Have, Poços de Caldas).

Nos quatro relatos supracitados, quem fala são sujeitos que viveram trajetórias pré- e pós-ocupação muito diferentes, assim como atuaram de modos diversos na ação coletiva. Ainda assim, seus relatos confluem em uma espécie de reconhecimento da igualdade de fala e do direito de ser ouvido e valorizado; na construção de si como sujeito político no protesto tanto contra o dano ou "lesão" quanto pela desidentificação em relação às funções sociais atribuídas a pessoas adolescentes e a estudantes, com sua condição de subcidadania. Para essas pessoas, mesmo que não tenham experimentado ou continuado com a militância em organizações políticas, a subjetivação política vivida no acontecimento das ocupações se mantém como potência, como força latente, muitas vezes expressa por elas, assim como por outras entrevistadas, em certas posturas consideradas progressistas ou emancipadas na vida cotidiana, como sexualidade, religiosidade e relações de trabalho e familiares. Em uma análise esperançosa, apontamos, enfim, a latência: o registro ou acúmulo, nas mentes e corpos, do tanto que ocupas aprenderam nos momentos, concentrados mas potentes, de subjetivação política, durante a ação coletiva, pôde se converter em prontidão ou abertura para a adesão - e até mesmo protagonismo - de novos movimentos insurgentes.

\section{Considerações Finais}

A ocupação pode ser considerada um processo de subjetivação política, no sentido dado por Jacques Rancière; ou seja, algo que acompanha a política em seu sentido dissensual. A política como dissenso, segundo 
Rancière, instaura um espaço provisório de igualdade, a despeito dos diferentes papéis sociais e das posições desiguais no espaço público que as pessoas ocupam na ordem policial, ordem essa que é suspensa ou deslocada por esse breve período em que as pessoas se tornam sujeitos políticos. Desse modo, as ocupações podem ser descritas como momento de suspensão ou deslocamento das identidades políticas delineadas pela ordem policial, assim como de outras identidades sociais, como a etária (adolescente), ocupacional (estudante), de gênero, étnica e de orientação sexual. Tais identidades, como vimos ao longo do artigo, podem vir a receber novos significados e até mesmo ser rompidas durante o dissenso, sem obrigatoriamente criar identidades estáveis.

Desse modo, diante do objetivo proposto de analisar os impactos da experiência de ocupar na formação política e nas trajetórias de ocupas, entre os resultados deste artigo, temos fortes indícios de que, ao longo da vida, em momentos diversos, a experiência de ter sido sujeito político durante as ocupações poderá ser mobilizada para decisões e tomadas de posição por essas pessoas. Na verdade, já vêm fazendo isso, em atitudes que vêm também indicando o transbordamento da experiência política para outras esferas da vida, elas próprias politizadas por ex-ocupas, como a educação, a arte, a carreira profissional, a orientação sexual, o trabalho e a família.

Outros resultados demonstram certa prontidão para a militância política, mas ela tendeu a não se manter: apenas um ocupa independente que se tornou militante continua a se identificar assim. Isso não significa rejeição das organizações políticas por esses sujeitos, já que, a rigor, apenas uma ocupa declarou sua ojeriza às juventudes partidárias. Como as relações entre ocupas e organizações durante o movimento indicaram, a tendência é de uma certa continuidade - com necessária rearticulação, dado o contexto político retrógrado - nas relações de colaboração (mais do que de conflito) vividas nas ocupações e em grandes manifestações em 2016 e 2017, de certa forma revividas no "Ele Não" em 2018.

Consideramos que as ocupações tenham promovido, sobretudo, experiências de subjetivação política - ainda que a UJS tenha procurado aproveitar a ação coletiva para consolidar o engajamento militante de duas estudantes. Como subjetivação política, constituíram agregados ou coletivos que tendiam a promover relações igualitárias entre seus membros, a despeito das suas diferentes posições etárias, ocupacionais e políticas. Ocupas também intentaram o reconhecimento da sua condição de igualdade - como pessoas com direito à palavra e à ação - perante a sociedade local e os governos.

Como vimos, nem todas as ocupações tiveram essa característica, em especial aquelas em que dada entidade estudantil ou juventude partidária desejou marcar - nem sempre com sucesso - sua posição perante o cenário político. Todavia, essas foram a minoria e, mesmo aí, por vezes, enfrentaram notável resistência de uma base independente.

Como processo de emersão de sujeitos políticos, as ocupações tornaram possível a ativa participação política de pessoas que, considerando os processos de socialização, em condições normais, dificilmente teriam tamanha experiência de atuação. É o caso especialmente de quem veio participar da ação depois que ela tinha começado, que não tinham se envolvido nem mesmo com as discussões preliminares do grêmio ou de quem iniciou o movimento. Mesmo em relação a quem tinha mais disposição ao engajamento e, por isso, ocupou posições de liderança ou esteve no movimento desde o seu início, essa participação singular, em um movimento ele próprio ímpar, rendeu vivência - ou, usando os termos de Thompson (2002), uma experiência modificada da sua condição social (estudantil, juvenil e "popular") $)^{4}$ - que dificilmente teria se dado na normalidade do cotidiano ou da ordem social instituída.

Na verdade, o próprio movimento das ocupações é singular, ímpar, inesperado e imprevisível, considerando as funções sociais atribuídas a estudantes, adolescentes das classes populares e jovens mulheres, bem como constantes crise, precariedade e falta de sentido com aquilo por que nos 
acostumamos a caracterizar as escolas públicas, loci das ações coletivas. Mais do que tentar explicar a origem ou as causas do movimento, buscamos entender como ele aconteceu, o que as pessoas fizeram com ele e o que podem vir a fazer dessa experiência. Nesse vir a ser, apostamos nossas esperanças.

\section{Contribuição dos Autores}

Problematização e Conceituação, Groppo LA; Metodologia, Groppo LA e Oliveira MA; Análise, Groppo LA e Oliveira MA; Redação, Groppo LA e Oliveira MA.

\section{Notas}

1. Até o momento, foram realizadas 61 entrevistas com ocupas em todas as regiões do país.

2. Lésbicas, Gays, Transgêneros e Transexuais.

3. O capital cultural se refere ao conjunto de qualificações intelectuais produzidas e transmitidas pela família e pelas instituições escolares, sob três formas: o estado incorporado, como disposição durável do corpo; o estado objetivo, como a posse de bens culturais; e o estado institucionalizado, sancionado pelas instituições, como os títulos acadêmicos.(BOURDIEU, 1998).

4. Confira a interessante análise das ocupações gaúchas, a partir desse conceito, feita por Borges e Silva (2019).

\section{Referências}

BORGES, S. G.; SILVA, R. M. D. Condição adolescente e socialização política nas ocupações secundaristas em Caxias do Sul, RS. Práxis Educativa, Ponta Grossa, v. 14, n. 3, p. 1-17, 2019. https://doi.org/10.5212/ PraxEduc.v.14n3.014

BOURDIEU, P. Escritos de educação. Petrópolis: Vozes, 1998.

BRENER, A. K. Socialização política nos percursos de jovens militantes de partidos políticos. In: CARRANO, P.; FAVERO, O. (orgs.). Narrativas juvenis e espaços públicos: olhares de pesquisa em educação, mídia e ciências sociais. Niterói: Editora da UFF, 2014. cap. 2, p. 31-54.

BRINGEL, B.; PLEYERS, G. Junho de 2013 ... dois anos depois: polarização, impactos e reconfiguração do ativismo no Brasil. Nueva Sociedade, San Jose, v. 30, n. 2, p. 4-17, 2015.

CASTRO, L. R. Juventude e socialização política: atualizando o debate. Psicologia: Teoria e Pesquisas, Brasília, v. 25, n. 4, p. 479-487, 2009. http://doi.org/10.1590/S0102-37722009000400003

CASTRO, L. R.; MATTOS, A. R. O que é que a política tem a ver com a transformação de si? Considerações sobre a ação política a partir da juventude. Análise Social, Lisboa, v. XLIV, n. 193, p. 793-823, 2009.

DAYRELL, J. O jovem como sujeito social. Revista Brasileira de Educação, Rio de Janeiro, v. 24, n. 2, p. 40-52, 2003. https://doi.org/10.1590/S1413-24782003000300004 
DURKHEIM, É. Educação e sociologia. 10. ed., São Paulo: Melhoramentos, 1978.

FILLIEULE, O. Propuestas para un análisis procesual del compromiso individual. Intersticios - Revista Sociológica de Pensamiento Critico. Murcia, v. 9, n. 2, 2015, p. 197-212.

GROPPO, L. A. et al. Ocupações no Sul de Minas: autogestão, formação política e diálogo intergeracional. ETD - Educação Temática Digital. Campinas, v.19 n.1 p. 141-164, 2017. https://doi.org/10.20396/etd. v19i1.8647616

GROPPO, L. A. et al. Coletivos juvenis políticos em uma universidade pública mineira: microespaço público e experiências de participação no movimento estudantil. Práxis Educativa. Ponta Grossa, v. 14, n. 3, 2019. https://doi.org/10.5212/PraxEduc.v.14n3.013

MAYORGA, C.; CASTRO, L. R.; PRADO, M. A. (orgs.). Juventude e a experiência da política no contemporâneo. Rio de Janeiro: Contracapa, 2012.

OPPO, A. Socialização política. In: BOBBIO, N.; MATTEUCCI, N.; PASQUINO, G. (org.). Dicionário de política. 11. ed. Brasília: Editora da UnB, 1998, p. 1202-1206.

RANCIÈRE, J. A noite dos proletários. Arquivos do sonho operário. São Paulo: Cia. das Letras, 1988.

RANCIÈRE, J. O desentendimento: política e filosofia. São Paulo: Editora 34, 1996.

RANCIÈRE, J. Nas margens do político. Lisboa: KKYM, 2010.

REGUILLO, R. Disidencia: Frente al Desorden de las Cajas Abiertas - México, Breve y Precario Mapa de lo Imposible. E-misférica, New York, v. 10, n. 2, 2013. Disponível em: http://hemisphericinstitute. org/hemi/es/e-misferica-102/reguillo. Acesso em: 10 fev. 2020.

SEIDL, E. Engajamento e investimentos militantes: elementos para discussão. In: CARRANO, P.; FAVERO, O. (orgs.). Narrativas juvenis e espaços públicos: olhares de pesquisa em educação, mídia e ciências sociais. Niterói: Editora da UFF, 2014. cap. 3, p. 55-70.

SWICKI, F.; SIMÉANT, J. Inventário da sociologia do engajamento militante. Nota crítica sobre algumas tendências recentes dos trabalhos franceses. Sociologias, Porto Alegre, ano 13, n. 28, set.-dez. 2011, p. 200-255, 2011. https://doi.org/10.1590/S1517-45222011000300008

THOMPSON, E. P. Educação e experiência. Os românticos: a Inglaterra na era revolucionária, Rio de Janeiro: Civilização Brasileira, 2002. p. 11-48.

TOMIZAKI, K.; DANILIAUSKAS, M. Os jovens e a política: do mal-estar a novas formas de expressão na vida pública. Entrevista com Anne Muxel. Pro-Posições, Campinas, v. 29, n. 1, 2018, p. 347-356. https://doi.org/10.1590/1980-6248-2016-0127

\section{Sobre os Autores}

Luís Antonio Groppo é doutor em Ciências Sociais pela Universidade Estadual de Campinas . É Professor da Universidade Federal de Alfenas, onde atua no Programa de Pós-graduação em Educação e coordena o Grupo de Estudos sobre a Juventude. É Pesquisador do Conselho Nacional de Desenvolvimento 
Científico e Tecnológico e Coordenador do GT 03 - Movimentos Sociais, Sujeitos e Processos Educativos, da Associação Nacional de Pós-graduação e Pesquisa em Educação, na gestão 2020-2021.

Mara Aline Oliveira é Graduada em Direito e Especialista em Filosofia pela Pontifícia Universidade Católica de Minas Gerais. Mestre em Educação pelo Programa de Pós-graduação em Educação da Universidade Federal de Alfenas. Atualmente, é advogada responsável pelo departamento jurídico da região Sul de Minas Gerais do Sindicato Único dos Trabalhadores em Educação de Minas Gerais.

Recebido: 09 jul. 2020

Aceito: 11 nov. 2020 